\title{
IgM memory and Waldenström macroglobulinemia's cell of origin
}

\author{
Fumou Sun ${ }^{1}$, Yan Cheng ${ }^{1}$, Siegfried Janz ${ }^{1,2}$ \\ ${ }^{1}$ Division of Hematology and Oncology, Department of Medicine; \\ ${ }^{2}$ Cancer Center, Medical College of Wisconsin, Milwaukee, WI 53226, USA.
}

\begin{abstract}
Waldenström macroglobulinemia (WM) is a neoplasm of mature IgM-expressing B-lymphocytes that is characterized by the occurrence of a monoclonal $\operatorname{IgM}(\mathrm{mIgM})$ paraprotein in blood serum and the infiltration of hematopoietic bone marrow with malignantly morphoplasmacytic cells. WM remains incurable despite the development of new therapeutic options. Owing in large measure to having alow incidence, indolent clinical course and good long-term control with proper clinical management, WM has not been investigated as extensively as other B-lineage neoplasms. Major knowledge gaps in our understanding of the natural history of WM include the cell of origin. With that shortcoming in mind, here we discuss the significance of a specific gain-of-function mutation in the adapter protein: myeloid differentiation primary response 88 (MYD88), that occurs with near-complete penetrance in WM and suggests that tumor development is under strong selective pressure for elevated MYD88 signaling. This provides an intriguing link to IgM memory B-cells, which comprises of two types of B-lymphocytes (natural effector $\operatorname{IgM}^{+} \operatorname{IgD}{ }^{+}$cells and IgM-only $\operatorname{IgM}^{+} \operatorname{IgD}{ }^{-}$cells) that depend, in part, on MYD88 signaling and constitute intriguing candidates for WM's cell of origin. We review the features and developmental history of IgM memory in greater depth and propose that WM may be derived from primitive innate-like B-cells (marginal zone B-cells and Bl B-cells) that feed the IgM memory compartment. We conclude with a model of MYD88-dependent tumor development in the mature B-cell lineagethat considers two different (convergent or divergent) oncogenesis pathways with respect to the cell of origin.
\end{abstract}

Keywords: waldenström macroglobulinemia; lymphoplasmacytic lymphoma;IgM paraprotein,Chronic Lympocytic leukemia

\section{WHY IS IT IMPORTANT TO IDENTIFY CANCER'S CELL OF ORIGIN?}

Defining the cell of origin in neoplastic development which leads to malignant growth in human beings is considered by many to be one of the most challenging tasks in cancer research ${ }^{[1]}$. Yet, this challenge is worth the effort because identifying cells of origin is crucially important for our understanding of the natural

\footnotetext{
*Correspondence to: Siegfried Janz, Division of Hematology and Oncology, Department of Medicine, Medical College of Wisconsin,Milwaukee, 8701 Watertown Plank Road, MFRC6033, Wauwatosa, WI 53226, USA.Tel: 414-955-5784, Fax: 414-9550036; E-mail: sjanz@mcw.edu
}

history of cancer (pathophysiology and -genesis) and the design and testing of new approaches to cancer treatment and prevention ${ }^{[2]}$. The poster child among blood cancers illustrating this point perhaps most beautifully is diffuse large B-cell lymphoma (DLBCL), a neoplasm of mature B-lymphocytes that is phenotypically and genetically heterogeneous. Gene-expression profiling has identified two major subgroups of DLBCL according to cell of origin: activated B-cell-like (ABC) and germinal-center B-cell-like (GCB). These tumors are associated with a differential response to therapy (both conventional chemo and targeted agents) and starkly different survival ${ }^{[3]}$. Combination therapy results in a $80 \%$ 3-year survival for patients with GCB- 
DLBCL, but achieves only a $~ 45 \%$ survival for patients with ABC-DLBCL.

During the past decades, a lot of research has been performed to elucidate the cell of origin for many other malignancies ${ }^{[4]}$. An important tool to that end is cell lineage tracing in laboratory animals, which is able to shed light on the cellular hierarchies and lineage segregation dynamics that govern tissue homeostasis and tissue repairat sites of cancer development ${ }^{[5]}$. If one extrapolates the basic research findings from animal models to human cancer, a picture emerges in which most malignancies originate from long-lived cells with self-renewal potential. Importantly, cells of this sort are not limited to tissue stem cells and early progenitors, but also include fully developed, long-lived lymphocytes that contain immunological memories. Memory cells are mature and differentiated, but are able to survive in specialized tissue sites for years on end,sometimes throughout the lifespan of the host ${ }^{[6]}$. Here we continue with an ongoing review of Waldenström macroglobulinemia (WM) that described clinical features ${ }^{[7]}$ and pathophysiological aspects ${ }^{[8]}$ of the $\mathrm{IgM}^{+}$lymphoplasmacytic lymphoma (LPL) in two previous publications in this journal. On this occasion we focus on the cellular origin of WM that has remained elusive thus far ${ }^{[9]}$.

\section{WM PRECURSORS MAY BE DERIVED FROM IGM ${ }^{+}$MEMORY CELLS}

Both the $\operatorname{IgM}{ }^{+} \operatorname{IgD}^{+} /^{-} \mathrm{CD} 27^{+} \digamma^{-}$immunophenotypic profile of WM cells, described in this journal in greater depth in a previous review ${ }^{[8]}$, and the occurrence of somatic mutations in IGV-encoded portions of the monoclonal IgM paraprotein of patients with $\mathrm{WM}$ have long been interpreted to mean that WM originates from a mature, antigen-experienced B-cell that exits the germinal center(GC) as an $\operatorname{IgM}^{+}$memory $\mathrm{B}$-cell ${ }^{[10]}$ that had engaged the somatic hypermutation (SHM) pathway of antibody affinity maturation but failed to perform class switch recombination (CSR a.k.a. isotype switching)that normally takes place in the course of the GC reaction ${ }^{[1]}$. This view, which implies that the WM precursor is a conventional follicular B-cell (often referred to as B2 cell) that has been recruited into a thymus-or T cell-dependent (TD) immune response, must be revisitedin light of recent progress in our understanding of the $\operatorname{IgM}^{+}$memory Bcell compartment, which has turned out to be more complex than previously known ${ }^{[12-14]}$. New pathways of $\operatorname{IgM}^{+} \mathrm{B}$-cell differentiation and $\operatorname{IgM}$ memory formation discovered in recent years ${ }^{[15-16]}$ include unconventional B-cells: includingmarginal zone (MZ) $\mathrm{B}$-cells and B1B-cells ${ }^{[17]}$. Just like the follicular cells mentioned above: $\mathrm{Z}$ and $\mathrm{B} 1 \mathrm{~B}$-cells can also give rise to IgM $\mathrm{M}^{+}$memory cells. The newly appreciated complexity of IgM memory has raised the bar for identifying the bonafide $\mathrm{M}$ precursor, assuming that only one precursor exists. It is also possible that the WM precursor pool is heterogeneous ${ }^{[10]}$, which may cause or at least contribute to the distinct molecular subtypes of WM identified in genome-wide studies of the tumor transcriptome $^{[18]}$.

The composition of IgM memory and the abundance of $\operatorname{IgM}^{+}$memory cells in the spleen and peripheral blood are schematically depicted in Fig.1. The scheme is based on the flow cytometric analysis of mature $\mathrm{CD} 19^{+} \mathrm{B}$-lymphocytes for expression of the memory B-cell marker, CD27, which identifies approximately $30 \%$ of cells as $\mathrm{CD} 27^{+}$memory Bcells ${ }^{[19]}$. The CD27 is a member of the tumor necrosis factor (TNF) receptor superfamily that binds to CD70, which is a member of the TNF ligand superfamily ${ }^{[19-20]}$. The $\mathrm{CD} 27^{+}$compartment is equally composed of "switched"IgM B-cells and "unswitched" $\operatorname{IgM}^{+}$Bcells. While the former have undergone CSR and thus express a post-switch isotype, such as IgG or IgA, the latter have not performed CSR and continue to express IgM. The $\mathrm{CD} 27^{+} \operatorname{IgM}{ }^{+}$compartment can be further divided based on expressionof IgD on the cell surface. $\operatorname{IgD}$ is found at low levels when B-lymphocytes exit the bone marrow and begin to populate peripheral lymphoid tissues, but is strongly upregulated when the cells reach full maturity in tissue sites. Double-positive $\operatorname{IgM}^{+} \operatorname{IgD}^{+}$or "natural effector" cells comprise the bulk of the CD27 $7^{+} \mathrm{IgM}^{+}$compartment (99\%), whereas single-positive $\operatorname{IgM}^{+} \operatorname{IgD}^{-}$cells, dubbed "IgM-only" B cells, -epresent but a minor population $(\geqslant 7 \%)^{[15]}$.

The light-blue box in Fig. 2 indicates that the $\operatorname{IgM}^{+}$ memory compartmentis likely to contain the elusive WM precursor, yet it cannot answer the question whether the malignant cell clone is derived from $\mathrm{IgM}^{-}$ only $\left(\operatorname{IgM}^{+} \operatorname{IgD}{ }^{-}\right)$memory or $\operatorname{IgM}^{+} \operatorname{IgD}{ }^{+}$memory cells. While the former nicely matches the $\mathrm{IgD}^{-}$phenotype of WM, these cells are rare to begin with. The problem with the latter is the postulation that $\operatorname{IgD}$ is down regulated or lost during malignant cell transformation. There is no direct evidence to support this contention, but empirical findings thata minority of WM cases $(5 \% \sim 10 \%)$ weakly express $\operatorname{IgD}$ is consistent with the possibility ${ }^{[8]}$. CD $20^{+} \operatorname{IgM}^{+} \operatorname{IgD}^{+}$B-cells have been implicated as WM precursors in past studies ${ }^{[21]}$. $\operatorname{IgM}^{+} \operatorname{IgD}{ }^{-} \mathrm{B}$-cells are thought to be products of a single source: primary GC reactions that engage conventional B-cells (B2 cells) in TD-dependent immune responses. In contrast, $\operatorname{IgM}^{+} \operatorname{IgD}{ }^{+} \mathrm{B}$-cells constitute a mixture of unconventional MZ and B1B-cells, with 
B2 cells making only a small if not negligible contribution ${ }^{[22]}$.The biological significance of IgM memory and its principal developmental pathways will be briefly discussed in the following.

\section{FEATURES AND COMPONENTS OF B- CELL MEMORY}

\section{B-cell memory is long lived and in- cludes a sizeable fraction of $\mathrm{IgM}^{+}$cells}

Human memory B-cells can survive for decades ${ }^{[23-25]}$. This is intriguing from a tumor development point of view because longevity can be expected to endow a putative target of neoplastic development with more opportunities to complete the time-consuming, multistep process of oncogenesis than available for a shortlived target cell. In other words, the life span of a non-memory, relatively short-lived B cell may simply be insufficient to accumulate all the genetic and epigenetic changes required for fully autonomous, malignant growth. Upon re-encounter with the antigen or hapten for which they exhibit immunologic specificity, memory B-cells can rapidly proliferate and differentiate into plasma cells that secrete highaffinity antibodies. Memory B-cells have classically been defined as antigen-experienced, long-lived $\mathrm{IgD}^{-}$ $\mathrm{B}$-cells that have undergone somatic mutations in their productively rearranged, expressed $\mathrm{IgV}$ genes. Additional characteristics include the presentation on the cell surface of the memory marker $\mathrm{CD} 27$, and of costimulatory and activation markers, such as CD95 (FAS receptor) and CD80/CD86, which are ligands for CD28/CD152 on T-cells, respectively. In contrast to these markers, the low-affinity IgE receptor, CD23, isdown regulated in memory B-cells ${ }^{[26,27]}$.

Recent work from several laboratories has demon strated that the memory B-cell population is phenotypically, functionally, and ontogenetically heterogeneous. Analysis of Ig expression patterns by antigenbinding $\mathrm{CD} 27^{+} \mathrm{B}$-cells revealed that a surprisingly large proportion of memory cells do not perform CSR of the expressed $\mathrm{H}$ chain and, therefore, continue to express IgM. This finding not only demonstrated the existence of IgM memory ${ }^{[28-29]}$ but also raised the question what the benefit for the host might be to maintain these cells for long periods of time. An important answer came from a study on mice, which showed that upon secondary challenge with antigen, the IgM and IgG memory subsets displayed differential effector functions: $\operatorname{IgG}^{+}$cells rapidly differentiated into plasma blasts, whereas $\operatorname{IgM}^{+}$cells acted again to initiate secondary GC reactions ${ }^{[30]}$. This suggested that $\mathrm{IgM}^{+}$cells may comprise a durable reserve for humoral immune responses that can be recalled at an indeterminate, later point in life. A related, independent study demonstrated that $\operatorname{IgM}^{+}$cells were longer lived than their $\mathrm{IgG}^{+}$counterparts, but responded to reencounter with the specific antigen in a different way: while the switched memory dominated the secondary immune response due to its capacity to become activated in the presence of neutralizing serum Ig, IgM ${ }^{+}$memory cells did not contribute to this response until after the switched memory cells disappeared and the Ig levels had declined ${ }^{[31]}$. This result led to the theory that $\operatorname{IgM}^{+}$memory is "waiting in the wings"as a back-up force of sorts-ready to spring into action when the switched memory fails to clear the antigen, but quietly staying in the background when the switched memory is able to take care of the job ${ }^{[31]}$.

\section{IgM-only memory B-cells}

The functional properties, subtypes, and developmental history of IgM memory cells have been worked out in some detail (Fig.1, blue box).Immunologists now divide $\mathrm{IgM}^{+}$memory $\mathrm{B}$-cells into two groups: "natural effector" cells, which will be described in the section below, and "IgM-only" cells, the source of which will be described in the following. Evidence provided by a Dutch group indicates that IgM-only or $\mathrm{CD} 27^{+} \operatorname{IgM}{ }^{+} \operatorname{IgD}{ }^{-}$memory B-cells originate from primary GC responses. Building on the widely accepted paradigm that extensive antigen-induced cell prolife ration and SHM are hallmarks of memory B-cells, the Dutch investigators developed two nifty molecular assays-called KREC (Ig-deleting recombination excision circle) and Ig REHMA (Ig restriction enzyme hot-spot mutation) that permit one to generate good estimates of a B-cell's replication history (i.e., number of cell divisions) and SHM history (i.e., number of somatic mutations in $\mathrm{IgV}$ genes), respectively ${ }^{[32]}$. KREC is a qPCR assay for determining the ratio of genomic coding and signal joints formed as a consequence of genetic inactivation of the IGK locus, which is accomplished by chromosomal rearrangements that delete the IGK constant region gene, $\mathrm{C}$, together with the downstream IGK enhancer, $3^{\prime} \mathrm{E}^{[32]}$. Ig REHMA is a DNA spectra typing assay that determines the mutational load in CDR1 (complementarity determining region 1) of the IGKV3-20 gene, which has been validated as a reliable indicator of overall SHM activity in expressedIg genes in vivo. The Dutch investigators found that "IgM only" B-cells had a replication and SHM history in line with GC B-cells, suggesting that $\mathrm{CD}_{27}{ }^{+} \mathrm{IgM}^{+} \operatorname{IgD}{ }^{-} \mathrm{B}$-cells are off spring of follicular Bcells that underwent $\mathrm{SHM}^{-}$mediated affinity increases 
in their $\mathrm{H}$ chains in the course of a primary $\mathrm{GC}$ response, but exited the GC prior to undergoing isotype switching. $\operatorname{IgM}^{-}$only memory B-cells match the $\mathrm{IgM}^{+} \operatorname{IgD}{ }^{-}$phenotype of frank WM and have been repeatedly shown to undergo expansion in patients with autoimmune diseases ${ }^{[33-34]}$, which is a known pathogenetic driver of WM based on epidemiologic findings ${ }^{[7]}$. On this backdrop, it seems reasonable to postulate that the natural history of WM may begin with an $\mathrm{IgM}^{-}$ only memory B-cell, even though these cells are rare under normal conditions (Fig.1).

\section{Natural effector memory B-cells}

$\mathrm{CD} 27^{+} \operatorname{IgM}{ }^{+}$memory B-cells that co-express IgD outnumber their IgD- counterparts in peripheral blood and spleen by approximately two orders of magnitude. $\mathrm{CD} 27^{+} \operatorname{IgM}^{+} \operatorname{IgD}{ }^{+}$or "natural effector" memory B-cells comprise a heterogeneous compartment that includes developmentally primitive, unconventional B-cells derived from MZ B-cells or B1 B-cells ${ }^{[15-16]}$. The "primitive" origin not withstanding, natural effector B-cells are thought to be genuine memory cells based on three lines of evidence.

Firstly, they express high levels of activation/costimulation molecules, such as CD80, CD180 (also known by the archaic term Bgp-9 $5^{[35]}$ ), and TACI [tumor necrosis factor (TNF) receptor superfamily, member 13B(TNFRSF13B)]. CD180 and TACI are of special interest because they induce cellular signal transduction pathways dependent on myeloid differentiation primary response 88 (MYD88). CD180, which associates with lymphocyte antigen 86 (LY86 a.k.a. MD-1) to form a cell surface receptor complex that belongs to the Toll-like receptor (TLR) family, works in concert with TLR4 to regulate B-cell activation in response tolipopolysaccharide (LPS), a membrane constituent of Gram-negative bacteria. TACI regulates humoral immunity by virtue of interacting with two TNF family ligands, BAFF (B-cell activating factor) and APRIL (a proliferation-inducing ligand). $\mathrm{BAFF}^{[36]}$ also known as TNF ligand superfamily, member 13B (TNFSF13B), B-lymphocyte stimulator (BLYS), TNF- and APOL-related leukocyte expressed ligand (TALL1) ${ }^{[37]}$,or cluster of differentiation 257 (CD257) is a cytokine that acts as a potent activator of $\mathrm{B}$-cells and plays an important role in the proliferation and differentiation of B-cells. APRIL- also referred to as the tumor necrosis factor ligand superfamily, member 13 (TNFSF13) or cluster of differentiation 256 (CD256), is important for the long-term survival of plasma cells in the bone marrow ${ }^{[38]}$. The BAFF/ APRIL/TACI/MYD88 axis is important for the development of natural effector cells and their function as memory cells.

Secondly, natural effector B-cells appear to be selected against inherently autoreactive $\mathrm{VH}$ domains, a general feature of memory B-cells. Consistent with that, the cells have an extensive replication history compared to naive B-cells (usingthe KREC assay) and exhibit SHM profiles of Ig heavy and light variable genes that are characterized by high R/S (replacement to substitution) ratios in $\mathrm{H}$ chain CDRs (Ig REHMA assay ${ }^{[22]}$. Natural effector B-cells were found to have proliferated somewhat less vigorously (7 cell divisions on average) than GC B-cells (9 divisions), but the mutational load in IGHV was comparable in the two cell types. This result lent additional support to the contention that a substantial fraction of $\mathrm{CD}^{2} 7^{+} \operatorname{IgM} \mathrm{IgD}^{+}$ memory B-cells is generated outside the GC, using a SHM pathway that operates independently of the GC reaction.

Thirdly, a recently reported high-throughput analysis of $\mathrm{V}_{\mathrm{H}}$ sequences from blood samples of three adult donors ${ }^{[39]}$ found major differences in the immunological repertoire of $\mathrm{CD}_{2} 7^{+} \mathrm{IgM}^{+} \mathrm{IgD}^{+} \mathrm{B}$-cells and $\mathrm{IgG}^{+}$or $\mathrm{IgA}^{+} \mathrm{B}$-cells. Compared to switched B-cells, natural effector B-cells exhibited a two fold higher usage of $\mathrm{V}_{\mathrm{H}} 3$ but a 20 -fold lower usage of $\mathrm{V}_{\mathrm{H}} 1$. The marked bias for $\left(\mathrm{V}_{\mathrm{H}} 3\right)$ and against $\left(\mathrm{V}_{\mathrm{H}} \mathrm{l}\right)$ heavy-chain gene families is strikingly similar to that seen in WM, raising the possibility that the same selective force might shape the repertoire of natural effector and WM cells ${ }^{[39]}$. The findings presented above lend credence to the proposal that WM may be derived from a natural effector B-memory cell.

\section{CONSTITUENTS OF NATURAL EF- FECT OR IGM ${ }^{+}$IGD $^{+}$MEMORY}

\section{MZ B-cells}

MZ B-cells are good candidates fordeveloping into natural effector memory B-cells using the MYD88TIRAP-IRAK4 pathway mentioned above ${ }^{[40]}$. Firstly, unlike laboratory mice, in which MZ B-cells express germline IGV genes, they reside in the splenic marginal zone and do not re-circulate ${ }^{[33]}$. Also MZ B-cells in human beings carry mutations in the IGV-encoded portions of the B-cell receptor and re-circulate in the blood stream ${ }^{[33]}$. The mutations in IGV genes appear to be of the more limited "extrafollicular variety" ${ }^{[22-33]}$ and are probably caused by a mechanism that involves recently discovered pathways of AID-dependent but T-cell- and GC-independent $\mathrm{SHM}^{[4]]}$. Consistent with the moderate mutational load in their expressed IGV genes, MZ B-cells contain molecular footprints of past proliferation in an extra follicular environment ${ }^{[22,42-44]}$. Prenatal 
studies have lent additional support to the notion that MZ B-cells are able to mutagenize IGV genes in the absence of GCs and independent of stimulation with antigen ${ }^{[22,42-44]}$. Secondly, the splenic marginal zone may be involved in induction of IGV mutations because it contains foci of proliferating clonally related B-cells that express AID ${ }^{[45-46]}$. These B-cells make use of a specialized T-cell independent (TI) pathway of SHM that involves the recognition of commensal antigens presented on neutrophil extracellular traps (NETs) formed by neutrophilsin in the the marginal or perimarginal zone. Neutrophils of this sort have been designated neutrophil B-cell helper $\left(\mathrm{N}_{\mathrm{BH}}\right)$ cells $^{[46]}$. Findings that SHM is decreased in the MZ B-cells of neutropenic patients ${ }^{[46]}$ underline the relevance of $\mathrm{N}_{\mathrm{BH}}$ cells. TLR signaling must be important for the $\mathrm{N}_{\mathrm{BH}}$ pathway of SHM, because results show that microbial TLR ligands control the number of splenic NBH cells with mutation-inducing activity ${ }^{[46]}$. There is also direct evidence that TLR ligationin MZ B-cell precursors induces $\mathrm{SHM}^{[47-48]}$. Thirdly, a group of investigators noticed that splenic $\mathrm{CD} 21^{+} \mathrm{CD} 27^{+} \mathrm{B} 220^{+} \mathrm{CD} 23^{-}$ MZ B-cells localize around the follicular B-cell zone in an area similar, but not identical to that of the marginal zone in mice and, hence,termed the cells MZanalog or MZA B-cells ${ }^{[49]}$. They found that MZA Bcells highly express TACI and BAFFR and are hyperresponsive to signals that mimic $\mathrm{T}$-cell activation ${ }^{[49]}$. They also reported that compared to switched IgMMZA B-cells, $\operatorname{IgM}^{+}$MZA B-cells respond poorly to inducers of plasmacytic differentiation in vitro ${ }^{[50]}$. This is reminiscent of the lymphoplasmacytic phenotype of WM cells, which appear torespond poorly to inducers of plasmacytic differentiation in vivo. In sum, a considerable body of circumstantial evidence suggests that splenic MZ B-cells circulatein the bloodstream as natural effector memory B-cells under normal steadystate conditions ${ }^{[40]}$.

\section{B1 B cells}

A human B-cell subset that is still somewhat controversial, but potentially important for the MYD88TIRAP-IRAK4-dependent natural effector memory $\mathrm{B}$-cell population is the Bl B-lymphocyte-the longsought-after equivalent of the mouse Bl B-cell lineage responsible for most of the spontaneous IgM production in mice. The human $\mathrm{B} 1$ subset, identified as $\mathrm{CD} 27^{+} \operatorname{IgD}{ }^{+} \mathrm{CD} 43^{+}$, displays typical characteristics of "primitive" or "innate-like" B-cells, including tonic BCR signaling, low levels of spontaneous $\operatorname{IgM}^{+}$ plasma cell production, and the intrinsic capacity to drive allogenic T-cell proliferation ${ }^{[51,52]}$. B1 B-cells perform a variety of biological functions including antigen presentation and priming of T-cells, but their principal role is the secretion of natural antibodies in the absence of exogenous antigenic stimulation ${ }^{[53]}$. Natural antibodies, which prominently include $\operatorname{IgM}$, are low-affinity, polyreactive immunoglobulins that use $\mathrm{H}$ chains that typically harbor only a minimal number of somatic mutations and few, if any, insertions of non-templated nucleotides at V(D)J junctions ${ }^{[54]}$. Natural antibodies provide instant defense against invading pathogens, and also prevent autoimmunity by virtue of inducing a non-inflammatory, non-immunogenic clearance pathway for altered self-antigens, including those found in apoptotic bodies ${ }^{[5]}$. Curiously enough, the $\mathrm{CD} 27^{+} \operatorname{IgD}{ }^{+} \mathrm{CD} 43^{+}$subset has been shown to comprise $\sim 40 \%$ of $\mathrm{CD} 27^{+} \mathrm{B}$-cells in adults, a proportion quite similar to the $\sim 50 \%$ unswitched $\mathrm{CD} 27^{+}$ $\mathrm{IgD}^{+} \mathrm{IgM}^{+}$cells shown above the colored box in Fig.1. The comparable abundance has raised questions as to whether B1 B-cells and natural effector B-cells are largely overlapping, and whether the contribution of $\mathrm{Bl}$ cells to the natural effector memory might be more substantial than assumed in the past. Although attempts have been made to essentially equate circulating B1 B-cells with the $\mathrm{CD}_{2} 7^{+} \operatorname{IgM}^{+} \operatorname{IgD}{ }^{+}$compartment ${ }^{[15]}$, this interpretation has been challenged by concerns about the true size of the human Bl Bcell population, particularly in adults and older people $^{[56-57]}$. Nonetheless, the possibility that B1 B-cells make a significant contribution to the natural effector $\mathrm{CD} 27^{+} \operatorname{IgM}^{+} \operatorname{IgD}{ }^{+}$memory cannot be rejected.

\section{MYD88 AT THE CROSSROADS OF NATURAL EFFECT OR MEMORY AND WM}

\section{Loss of MYD88 signaling negatively impacts natural effector memory cell pool}

Inherited immunodeficiency disorders can be considered experiments of nature, permitting us to glean insights into pathways of immunity that would be difficult to discern in immunocompetent individu$\mathrm{als}^{[58-59]}$. This is particularly true for IgM memory, the understanding of which has been greatly aided by studies on patients who harbor rare genetic defects in immune genes governing memory responses. An important early clue was obtained in investigations of hereditary deficiencies in GC formation caused by lack of $\mathrm{CD} 40^{-} \mathrm{CD} 154$ signaling during cognate $\mathrm{B}$-and $\mathrm{T}$-cell interaction at the outset of the GC reaction. The number of $\mathrm{CD} 27^{+} \operatorname{IgM}{ }^{+} \operatorname{IgD}{ }^{+}$ memory B-cells are significantly reduced in these patients, yet these cells do not completely disappear 


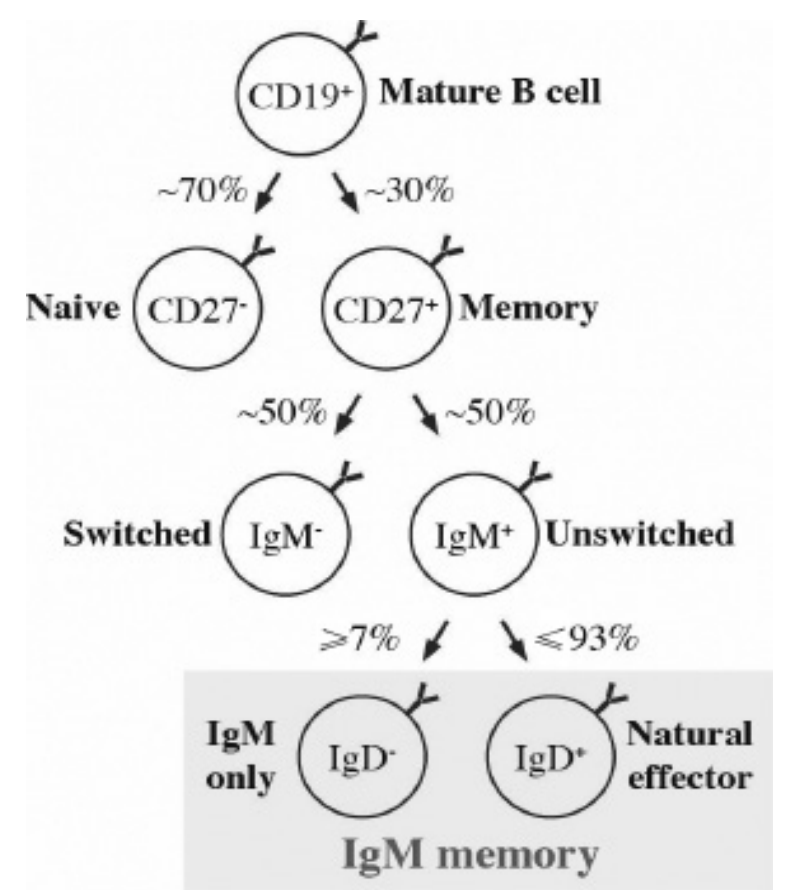

Figure 1. IgM memory in healthy human beings. Of human splenic and peripheral blood B-cells, $\sim 70 \%$ are $\mathrm{CD} 27^{+}$ and $\sim 30 \%$ are $\mathrm{CD} 27^{+}$. The $\mathrm{CD} 27^{+}$cells comprise a mixed population that contains both naïve $\operatorname{IgM}^{+} \mathrm{B}$-cells that express germ line $\mathrm{IgV}$ genes and $\mathrm{IgG}^{+} / \mathrm{IgA}^{+}$memory B-cells harboring mutated IgV genes (not shown). Naïve B-cells have not yet participated in an immune response and have not yet modified their expressed $\operatorname{IgV}$ genes, using the somatic hypermutation (SHM) pathway. In contrast, memory B-cells are immunologically experienced and have engaged the SHM machinery to increase the affinity of the expressed $\operatorname{IgV}$ gene to the underlying antigen. The CD27 $7^{+}$compartment is equally composed of "switched" IgM- B-cells and "unswitched" $\operatorname{IgM}^{+}$B-cells. The former have performed heavy-chain $(\mathrm{H})$ class switch recombination (CSR) having thereby, replaced $\mathrm{H}$ with $\mathrm{H}$. The latter have not undergone CSR. The great majority of $\mathrm{CD} 27^{+} \mathrm{IgM}^{+}$ cells co-express $\operatorname{IgD}\left(\operatorname{IgM}^{+} \operatorname{IgD}{ }^{+}\right)$; these cells comprise the "natural effector" memory. $\mathrm{CD}_{2} 7^{+} \mathrm{IgM}^{+} \operatorname{IgD}{ }^{-} \mathrm{B}$-cells (usually known as "IgM-only" cells) are rare comparedto $\mathrm{IgD}^{+}$natural effector counterparts. It should be acknowledged that there is a great deal of uncertainty about the true abundance of the IgM-only subset, with the $7 \%$ indicated in the figure probably definingthe lower limit. Depending on technical details of flow cytometric methods employed (e.g., gating strategies and antibodies), other studies arrived at ratios of "IgM-only" to "natural effector" cells that approach one to one as upper limit.

from peripheral blood ${ }^{[42,60-61]}$. The finding suggested that $\mathrm{CD} 27^{+} \operatorname{IgM}{ }^{+} \operatorname{IgD}^{+}$memory B-cells are normally generated using both GC-dependent and independent pathways. Postulating that the latter include pattern recognition receptors of the Toll-like receptor (TLR) family, investigators analyzed peripheral Bcell subsets in patients exhibiting genetic defects in TLR signaling. Deficiencies along this line affected

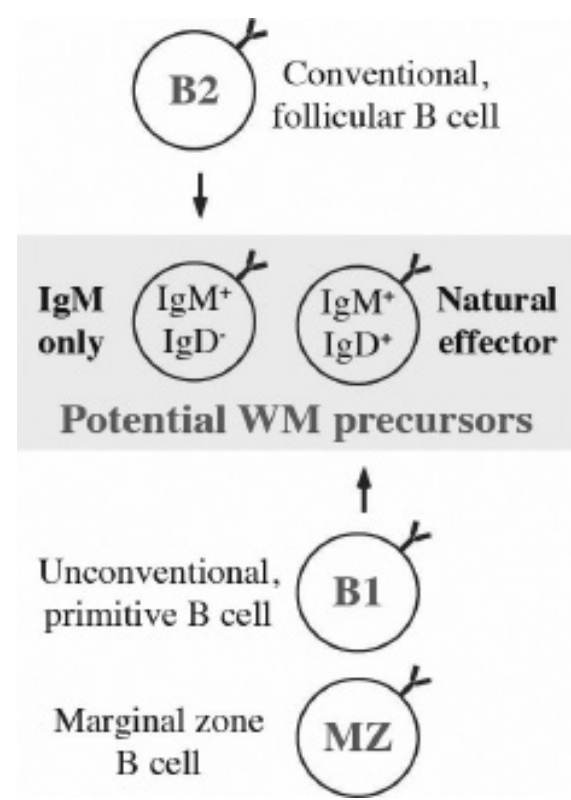

Figure 2. Sources of $\operatorname{IgM}^{+}$memory B cells. CD2 $7^{+} \operatorname{IgM}{ }^{+}$ $\mathrm{IgD}^{+}$"natural effector" memory B-cells and $\mathrm{CD} 27^{+} \operatorname{IgM}^{+} \operatorname{IgD}{ }^{-}$ "IgM-only" memory B-cells are candidate precursors of WM. The IgM-only component of $\operatorname{IgM}$ memory is better defined than the natural effector component, because it originates from a single source: primary GC responses that recruit B2 cells and often lead to hypermutated IGKV3-20 alleles. Natural effector cells are mostly derived from marginal zone (MZ) and $\mathrm{B} 1 \mathrm{~B}$-cells. The occurrence of somatic mutations in IGV genes expressed in $\mathrm{CD}_{2} 7^{+} \mathrm{IgM}^{+} \mathrm{IgD}^{+}$memory B-cells has fostered the hypothesis that these cells may participate in $\mathrm{GC}$ reactions, but leave the GC prematurely after undergoing moderate levels of SHM and avoiding $\mathrm{CSR}^{[62]}$. This interpretation does not reject the theory that $\mathrm{MZ}$ and $\mathrm{B} 1 \mathrm{~B}$-cells constitute GC-independent $B$-cell diversification pathways ${ }^{[63]}$, but questions whether the formation and maintenance of natural effector memory is possible without GC involvement ${ }^{[64]}$. To further complicate the picture, it is possible that additional subtypes of innate-like $\mathrm{B}$-cells exist that may feed the natural effector memory Bcell compartment. A case in point is the $\mathrm{CD} 21^{\text {low }} \mathrm{CD} 23-\mathrm{CD}$ $\mathrm{CD} 6^{\text {hi }} \mathrm{B}$-cell that expresses $\operatorname{IgM}$ and $\operatorname{IgD}$ with minimal $38^{\text {low- }}$ or no mutations ${ }^{[65]}$. These cells were first identified in patients with common variable immunodeficiency (CVID), especially in those with splenomegaly and granulomatous disease ${ }^{[66]}$, but later found to be abnormally elevated in other tissuesites ${ }^{[65]}$. In theory, it is easy to imagine that different types of B-cells and biological pathways of B-cell development overlap to shape the immune repertoire of natural effector memory B-cells. Slow, ongoing induction of SHM via TI pathways, triggered by signals from commensal microbial products may cooperate with immunization- or infection-dependent stimuli that rely on both extrafollicular TI and follicular TD pathways. The combination of these pathways would ensure the development of a highly diversified repertoire of ready-to-use innate-like natural effector cells ${ }^{[65]}$, some of which may go on to become precursors of WM. The considerations above not withstanding, the weight of evidence favors MZ and Bl cells as the main source of natural effector memory. 
(1) TLR3, one of ten TLRs expressed in human beings, (2) three different adapter proteins:MYD88, tollinterleukin 1 receptor domain containing adaptor protein (TIRAP) and toll-like receptor adaptor molecule 1 (TICAM), and (3) aprotein kinase important for signal transduction downstream of MYD88: interleukin-1 receptor-associated kinase 4 (IRAK4). In order to put the biological consequences of these genetic defects into perspective, it is important to realize that, firstly, all TLRs except TLR3 rely on MYD88 and IRAK4 for signal transduction, and secondly, TIRAP is additionally important for signaling induced by TLR4 homodimers and the heterodimers TLR2 forms with TLR1, TLR6 and, possibly, TLR10. The important finding for the purpose of this review is that loss of MYD88 function (schematically depicted in Fig. 3) or loss of IRAK4 and TIRAP function (not shown)leads to significant reductionsof $\mathrm{CD}_{2} 7^{+} \operatorname{IgM}{ }^{+} \operatorname{IgD}{ }^{+}$memory B-cells, but leaves their $\mathrm{IgD}^{-}$counterparts unchanged. Thus, MYD88-TIRAP-IRAK4 is the first genetic pathway specifically required for $\mathrm{CD} 27^{+} \operatorname{IgM}{ }^{+} \operatorname{IgD}{ }^{+}$ memory ${ }^{[67]}$. It indicates that pattern recognition receptor signaling via MYD88-using either MYD88 homodimers or MYD88/TIRAP heterodimers-promotes the homeostatic maintenance of memory B-cells that do not depend on T-cell help for activation and survival.

\section{WM cells contain a gain-of-function MYD88 mutant protein}

The dependenceof natural effector memory Bcellson MYD88-TIRAP-IRAK4 signaling provided an intriguing link to the natural history of WM when pioneering work at the Dana-Farber Cancer Institute (DFCI) in Boston, Massachusetts, put MYD88 at the center stage of WM development. The DFCI investigators demonstrated that the great majority of IgM ${ }^{+} L P L$ contains a specific somatic point mutation in the protein-encoding portion of the MYD88 gene, which replaced a leucine (L) residue at position 265 of MYD88 with a proline (P) residue (Fig.3). The highly recurrent exchange was uncovered by nextgeneration whole-genome sequencing and then confirmed using conventional Sanger sequencing ${ }^{[68]}$.The mutation and the resulting tumor allele are designated L265P and MYD88L265P, respectively. L265P resides in the TIR domain of the MYD88 protein, which interacts with TIR domains of various membrane receptors involved in innate immune responses, such as TLRs, IL-IR and IL-18R. The occurrence of the L265P mutation has been confirmed inindependent studies, reporting incidence rates in WM patients that range from $70 \%$ to $100 \%^{[71-74]}$. MYD88 ${ }^{\mathrm{L} 265 \mathrm{P}}$ is a gain-of-function mutation
TLR

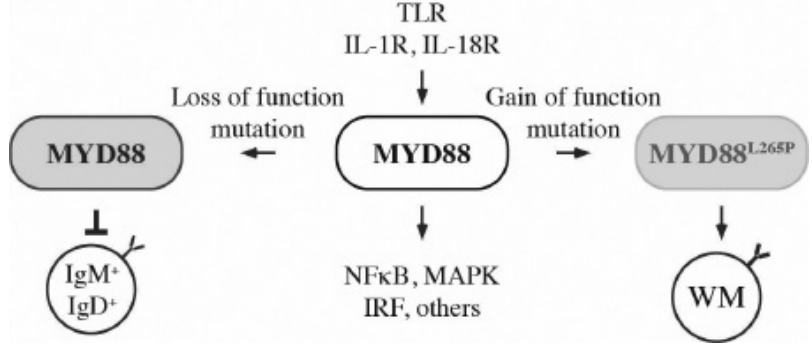

Figure 3. Mutations in MYD88 reveal an intriguing link of WM and natural effector IgM memory. Shown in the center is that normal B-lymphocytes and other cells of the immune system use MYD88 as a signaling adaptor protein that activates the nuclear factor $\kappa \mathrm{B}(\mathrm{NF} \kappa \mathrm{B})$, mitogenactivated protein kinase (MAPK), interferon regulatory factor (IRF) and other pathways following stimulation of receptors from the Toll/interleukin-1 receptor (TIR) superfamily:Tolllike receptors (TLRs) and receptors for interleukins $1(\mathrm{IL}-1 \mathrm{R})$ and 18 (IL-18R). MYD88 coordinates the assembly of a multiprotein signaling complex that contains members of the IRAK (interleukin-1 receptor-associated kinase) family of serinethreonine kinases.Upon ligand binding to TIRs, MYD88 is recruited, by virtue of homotypicTIR domain interaction, to the cell membrane-bound receptor complex. In turn, this leads tothe recruitment of IRAK4, which activates IRAK1 and IRAK2 by the phosphorylation of serine and threonine residues ${ }^{[69-70]}$. IRAK1-dependent activation of tumor necrosis factor receptorassociated factor 6 (TRAF6) effects ubiquitylation and activation of nuclear receptor subfamily 2 group $\mathrm{C}$ member 2 , better known as TGF- $\beta$-activated kinase 1 (TAK1); canonical NFKB activation, via the phosphorylation of $I \kappa B \alpha$; and the execution of theNFkB-dependent gene regulation program. Depicted to the left is the circumstance that genetic loss of MYD88 function (indicated in blue) leads to a significant reduction in $\mathrm{CD}_{27} 7^{+} \operatorname{IgM}{ }^{+} \operatorname{IgD}{ }^{+}$memory B-cells. This shows that MYD88 is essential for homeostatic maintenance of the natural effector memory. Shown to the right is the recent discovery that WM cells harbor in $~ 95 \%$ of cases, a highly recurrent gain-offunction exchange, L265P, in the hydrophobic core of the TIR domain of the MYD88 adaptor protein (red). This mutation facilitates homotypic interaction with the TIR domain of TIR family receptors and results in elevated or constitutive MYD88 signaling in the tumor cells.

that causes elevated TLR and interleukin signaling ${ }^{[75]}$. Following receptor stimulation, MYD88 is recruited to the activated receptor complex as a homodimer, which then complexes with IRAK4 to activate IRAKI and IRAK $2^{[69-70]}$. This leads to IRAK1-dependent phosphorylation of tumor necrosis factor receptor-associated factor 6 (TRAF6), which results in nuclear factor $\kappa \mathrm{B}(\mathrm{NF} \kappa \mathrm{B})$ activation via I $\mathrm{B}$ a phosphorylation (Fig. 3). NFKB is essential for growth and survival of WM cells. Inhibition of MYD88 signaling inhibits L265Pmutated WM cells by blocking I $\mathrm{K} \mathrm{B}$ a phosphorylation and nuclear translocation of transcriptionally active NF- $k B$ dimers ${ }^{[67]}$. Bruton tyrosine kinase also contrib- 
utes to MYD88-dependent activation of NFKB in the WM cell that harbors the L265P mutation ${ }^{[74]}$. These new insights into MYD88 signaling in WM have already led to new treatments for patients with $\mathrm{WM}^{[76]}$ and have spurred new ideas to further improve the quality of life,survival and outcome of WM as we go forward $^{[77]}$.

\section{MYD88 ${ }^{\mathrm{L} 265 \mathrm{P}}$ may drive divergentand conver- gent oncogenesis in the mature $B$-lineage}

Although highly recurrent in WM, the MYD88 ${ }^{\mathrm{L} 265 \mathrm{P}}$ allele is neither specific for, nor was it discovered in this disease. Instead, MYD88 ${ }^{\mathrm{L} 265 \mathrm{P}}$ was first detected in the ABC subtype of diffuse large B-cell lymphoma and later shown to be also present in primary central nervous system lymphoma (PCNSL); splenic marginal zone lymphoma (SMZL); mucosa-associated lymphoid tissue lymphoma (MALT); WM-related disease, IgM-associated light chain amyloidosis; and, rarely, chronic lymphocytic leukemia (CLL) ${ }^{[78-82]}$. Interestingly, the L265P exchange also occurs in the WM precursor condition, IgM-MGUS(monoclonal gammopathy of undetermined significance), indicating that it is an early event in the natural history of the disease ${ }^{[83]}$. Taken together, the clinical findings strongly suggest that the MYD88 ${ }^{\mathrm{L} 265 \mathrm{P}}$ adapter protein is conducive to the malignant transformation of different subtypes of mature B-lymphocytes: a classic example of divergent oncogenesis (Fig. 4). Considering the heterogeneity of IgM memory described above, it is also possible that MYD88 ${ }^{\mathrm{L} 265 \mathrm{P}}$ supports convergent cancer development. Thus, distinct subtypes of IgM memory B-cells may be able to acquire and tolerate the MYD $88^{\mathrm{L} 265 \mathrm{P}}$ mutation, and then converge on pathways of tumor development that yield the same tumor: WM (Fig. 4). Precedence for convergent tumorigenesis in cancer is plentiful, including well-documented examples for brain tumor, medulloblastoma ${ }^{[84]}$, and skin cancer and Merkel cell carcinoma ${ }^{[85]}$.

\section{KEY POINTS AND FUTURE DIRECTIONS}

Unlike "IgM-only" $\operatorname{Ig} \mathrm{M}^{+} \operatorname{Ig} \mathrm{D}^{-}$memory B-cells, "natural effector"IgM $\operatorname{IgD}^{+}$memory B-cells depend on MYD88 signaling for development and/or survival. Natural effector B-cells are thought to be derived from $\mathrm{MZ}$ and $\mathrm{B} 1 \mathrm{~B}$-cells, but opposing views considering follicular and other types of B-cells also exist. Regardless how this puzzle may be resolved by future research, the disappearance of natural effector cells under conditions of MYD88 deficiency and the strong selection for the MYD88 ${ }^{\mathrm{L} 265 \mathrm{P}}$ gain-of-function allele in WM, support the hypothesis that WM may

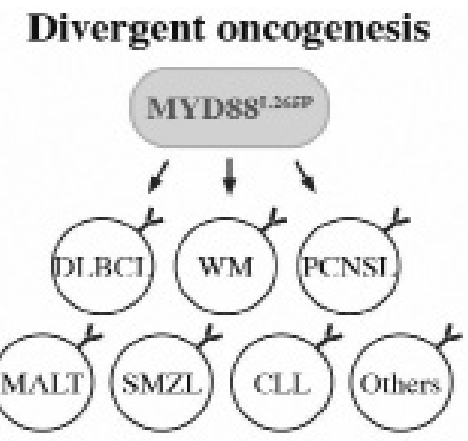

\section{Convergent oncogenesis}

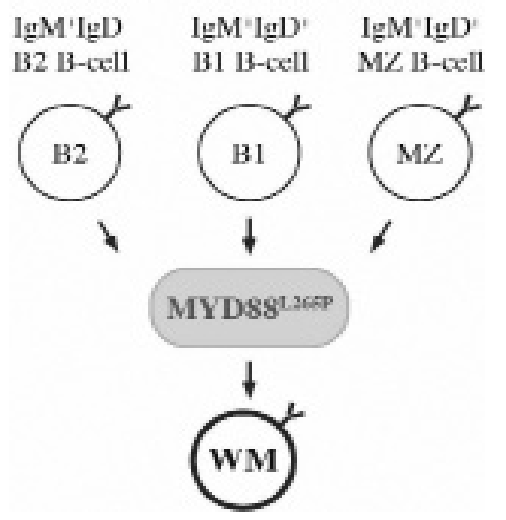

Figure 4. Genetic pathways of MYD88 $8^{\mathrm{L} 265 \mathrm{P}}$-driven neoplastic B-cell development. Depicted in the upper half is a scheme of divergent tumor development driven by the MYD88 ${ }^{\mathrm{L} 265 \mathrm{P}}$ mutation. Evidence indicates that $\mathrm{L} 265 \mathrm{P}$ substitution is the most common and most oncogenic representative of a variety of mutations that occur in the MYD88 gene, in neoplasms of the B-cell lineage. Subsequent to its discovery in ABC-DLBCL ${ }^{[79]}$, the MYD88 ${ }^{\mathrm{L265P}}$ mutation has also been found in the great majority of patients with $\mathrm{WM}^{[68]}$ and a fraction of patients with primary central nervous system lymphoma ( $\sim 35 \%)$, splenic marginal zone lymphoma ( 15\%), gastric mucosa-associated lymphoid tissue lymphoma ( 9\%), and chronic lymphocytic leukemia $(\sim 3 \%)$. The broad involvement of MYD88 ${ }^{\mathrm{L265P}}$ in subsets of mature B-lineage neoplasms, is reminiscent of divergent blood cancer development driven by BCR-ABL fusion proteins following chromosomal translocation. When gene fusion occurs in hematopoietic stem cells, it results in chronic myeloid leukemia $(\mathrm{CML})^{[86]}$, but when it occurs in lymphoid stem cell progenitors, it leads to B-cell acute lymphoblastic leukemia (B-ALL) ${ }^{[87]}$. Shown in the lower half is a model of MYD88 ${ }^{\mathrm{L} 265 \mathrm{P}}$-driven convergent cancer development relevant for WM. The model postulates that the acquisition of the MYD88 ${ }^{\mathrm{L} 265 \mathrm{P}}$ mutation by distinct IgM memory B-cells leads to a convergent tumor precursor state that goes on to progress to the same type of cancer: WM. Evidence for convergent tumorigenesis is available for the brain cancer,medulloblastoma, in which deletion of patched homolog 1 (PTCl) results in aggressive medulloblastoma regardless of whether the genetic change occurs in neural stem cells or granule neural precursors ${ }^{[84]}$. Convergent cancer development therefore requires that the transcriptomic and epigenetic profile of distinct cells of origin is permissive for a given oncogenic mutation. 
originate from primitive, natural antibody-producing B-lymphocytes that are dependent on MYD88 signaling for homeostatic maintenance and are susceptible to neoplastic development upon the acquisition of the MYD88 ${ }^{\mathrm{L} 265 \mathrm{P}}$ mutation. Going forward, experimental model systems including genetically engineered mice ${ }^{[88]}$ may be key for elucidating the mechanism by which MYD88 promotes natural effector cells and MYD88 $^{\mathrm{L} 265 \mathrm{P}}$ drives WM and related B-cell tumors.

\section{References}

[1] Rycaj K, Tang DG.Cell-of-Origin of cancer versus cancer stem cells: assays and interpretations[J]. Cancer Res,2015,75(19):4003-4011

[2] Blanpain C. Tracing the cellular origin of cancer[J]. Nat Cell Biol, 2013,15(2):126-134

[3] Schmitz R, Wright GW, Huang DW, et al. Genetics and pathogenesis of diffuse large B-Cell lymphoma[J]. $N$ Engl J Med, 2018,378(15):1396-1407

[4] Sanchez-Danes A, Blanpain C. Deciphering the cells of origin of squamous cell carcinomas[J]. Nat Rev Cancer, 2018,18(9):549-561

[5] Van Keymeulen A, Blanpain C. Tracing epithelial stem cells during development, homeostasis, and repair[J]. $J$ Cell Biol.,2012,197(5):575-584

[6] Seifert M, Kuppers R. Human memory B cells[J]. Leukemia, 2016,30(12):2283-2292

[7] Janz S. Waldenström macroglobulinemia-definition,symptoms, and treatment[J]. Asia Pac J Blood Types Genes, 2017, 1(4):3-11

[8] Janz S.Waldenström macroglobulinemia-immunophenotype and natural history[J]. Asia Pac J Blood Types Genes, 2018,2(2):1-9

[9] Growkova K, Kryukova E, Kufova Z, et al. Waldenstroms macroglobulinemia: Two malignant clones in a monoclonal disease? Molecular background and clinical reflection[J]. Eur J Haematol, 2017,99(6):469-478

[10] Garcia-Sanz R, Jimenez C, Puig N, et al. Origin of waldenstrom's macroglobulinaemia[J]. Best Pract Res Clin Haematol, 2016,29(2):136-147

[11] Sahota SS, Forconi F, Ottensmeier CH, et al. Origins of the malignant clone in typical Waldenstrom's macroglobulinemia[J]. Semin Oncol, 2003,30(2):136-141

[12] Kenderes KJ, Levack RC, Papillion AM, et al. T-Bet(+) IgM memory cells generate multi-lineage effector B cells[J]. Cell Rep, 2018,24(4):824

[13] Winslow GM, Papillion AM, Kenderes KJ, et al. CDllc+ T-bet+memory B cells:Immune maintenance during chronic infection and inflammation?[J]. Cell Immunol, 2017,321:8-17.

[14] Papillion AM, Kenderes KJ, Yates JL. Early derivation of IgM memory cells and bone marrow plasmablasts[J]. PLoS One, 2017,12(6):e0178853

[15] Reynaud CA, Descatoire M, Dogan I, et al. IgM memory B cells: a mouse/human paradox[J]. Cell Mol Life Sci, 2012,69(10):1625-34.
[16] Good-Jacobson KL, Tarlinton DM. Multiple routes to Bcell memory[J]. Int Immunol, 2012,24(7):403-408

[17] Prieto JMB, Felippe MJB. Development, phenotype, and function of non-conventional B cells[J]. Comp Immunol Microbiol Infect Dis, 2017,54:38-44.

[18] Paiva B, Corchete LA, Vidriales M, et al. The cellular origin and malignant transformation of Waldenstrom macroglobulinemia[J]. Blood, 2015,125(15):2370-2380

[19] Klein U, Rajewsky K, Kuppers R. Human immunoglobulin $(\operatorname{Ig}) \mathrm{M}(+) \operatorname{IgD}(+)$ peripheral blood B cells expressing the CD27 cell surface antigen carry somatically mutated variable region genes: CD27 as a general marker for somatically mutated (memory) B cells[J]. J Exp Med,1998,188(9):1679-1689.

[20] Tangye SG, Liu YJ, Aversa G, et al. Identification of functional human splenic memory B cells by expression of CD148 and CD27[J]. J Exp Med,1998,188(9):16911703

[21] Kriangkum J, Taylor BJ, Reiman T, et al. Origins of Waldenstrom's macroglobulinemia: does it arise from an unusual B-cell precursor?[J]. Clinical lympho$m a, 2005,5(4): 217-9$.

[22] Berkowska MA, Driessen GJ, Bikos V, et al. Human memory $B$ cells originate from three distinct germinal center-dependent and-independent maturation pathways[J]. Blood, 2011,118(8):2150-2158

[23] Crotty S, Felgner P, Davies H, et al. Cutting edge: long-term B cell memory in humans after smallpox vaccination[J]. J Immunol, 2003,171(10):4969-4973.

[24] Mamani-Matsuda M, Cosma A, Weller S, et al. The human spleen is a major reservoir for long-lived vaccinia virusspecific memory B cells[J]. Blood, 2008,111(9):4653-4659

[25] Amanna IJ, Carlson NE, Slifka MK. Duration of humoral immunity to common viral and vaccine antigens[J]. $N$ Engl J Med, 2007,357(19):1903-1915

[26] Zotos D, Tarlinton DM. Determining germinal centre B cell fate[J]. Trends Immunol, 2012,33(6):281-288

[27] Peperzak V, Vikstrom IB, Tarlinton DM. Through a glass less darkly: apoptosis and the germinal center response to antigen[J]. Immunol Rev, 2012,247(SI):93106

[28] Klein U, Kuppers R, Rajewsky K. Evidence for a large compartment of IgM-expressing memory B cells in humans[J]. Blood, 1997,89(4):1288-1298

[29] White H, Gray D. Analysis of immunoglobulin(Ig)isotype diversity and IgM/D memory in the response to phenyl-oxazolone[J]. J Exp Med, 2000,191(12):22092220

[30] Dogan I, Bertocci B, Vilmont V, et al. Multiple layers of B cell memory with different effector functions[J]. Nat Immunol, 2009,10(12):12U9-1292

[31] Pape KA, Taylor JJ, Maul RW, et al. Different B cell populations mediate early and late memory during an endogenous immune response[J].Science (80),2011,331(621):1203-1207

[32] Van Zelm MC, Szczepanski T, Van Der Burg MA. Replication history of B lymphocytes reveals homeostatic proliferation and extensive antigen-induced $\mathrm{B}$ cell 
expansion[J]. J Exp Med, 2007 ,204(3):645-655.

[33] Weller S, Braun MC, Tan BK, et al. Human blood IgM "memory" B cells are circulating splenic marginal zone B cells harboring a prediversified immunoglobulin repertoire[J]. Blood, 2004,104(12):3647-3654.

[34] Wei C, Anolik J, Cappione A, et al. A new population of cells lacking expression of CD27 represents a notable component of the B cell memory compartment in systemic lupus erythematosus[J]. J Immunol,2007,178(10):6624-6633

[35] Miura Y, Shimazu R, Miyake K, et al. RP105 is associated with MD- 1 and transmits an activation signal in human B cells[J]. Blood,1998,92(8):2815-2822

[36] Schneider P, Mackay F, Steiner V, et al. BAFF, a novel ligand of the tumor necrosis factor family, stimulates B cell growth[J]. J Exp Med, 1999,189(11):1747-1756

[37] Shu HB, Hu WH, Johnson H. TALL-1 is a novel member of the TNF family that is down-regulated by mitogens[J].J Leukoc Biol,1999,65(5):680-683

[38] Moreaux J, Legouffe E, Jourdan E, et al. BAFF and APRIL protect myeloma cells from apoptosis induced by IL-6 deprivation and dexamethasone[J]. Blood, 2004,103:3148-57

[39] Wu YC, Kipling D, Leong HS, et al. High-throughput immunoglobulin repertoire analysis distinguishes between human IgM memory and switched memory B-cell populations[J]. Blood, 2010,116(7):1070-1078

[40] Zhao Y, Uduman M, Siu JH, et al. Spatiotemporal segregation of human marginal zone and memory B cell populations in lymphoid tissue[J]. Nat Commun, 2018,9(1):3857

[41] Keim C, Kazadi D, Rothschild G, et al. Regulation of AID, the B-cell genome mutator[J]. Genes Dev, 2013,27(1):1-17

[42] Weller S, Faili A, Garcia C, et al. CD40-CD40L Independent Ig gene hypermutation suggests a second B cell diversification pathway in humans[J]. Proc Natl Acad Sci U S A, 2001,98(3):1166-1170

[43] Weller S, Mamani-Matsuda M, Picard C, et al. Somatic diversification in the absence of antigen-driven responses is the hallmark of the $\operatorname{IgM}^{+} \operatorname{IgD}{ }^{+} \mathrm{CD} 27^{+} \mathrm{B}$ cell repertoire in infants[J]. J Exp Med, 2008,205(6):1331-1342

[44] Scheeren FA, Nagasawa M, Weijer K, et al. T cellindependent development and induction of somatic hypermutation in human $\operatorname{IgM}(+) \operatorname{IgD}(+) \mathrm{CD} 27(+)$ B cells $[\mathrm{J}]$. J Exp Med, 2008,205(9):2033-2042

[45] Tierens A, Delabie J, Michiels L, et al. Marginal-zone B cells in the human lymph node and spleen show somatic hypermutations and display clonal expansion[J]. Blood,1999,93(1):226-234

[46] Puga I, Cols M, Barra CM, et al. B cell-helper neutrophils stimulate the diversification and production of immunoglobulin in the marginal zone of the spleen[J]. Nat Immunol, 2012,13(2):170-180

[47] Capolunghi F, Cascioli S, Giorda E, et al. CpG drives human transitional B cells to terminal differentiation and production of natural antibodies[J]. J Immunol,
2008,180(2):800-808

[48] Aranburu A, Ceccarelli S, Giorda E, et al. TLR ligation triggers somatic hypermutation in transitional B cells inducing the generation of IgM memory B cells[J]. J Immunol, 2010,185(12):7293-7301.

[49] Ettinger R, Sims GP, Robbins R, et al. IL-21 and BAFF/ BLyS synergize in stimulating plasma cell differentiation from a unique population of human splenic memory B cells[J]. J Immunol, 2007,178(5):2872-2882

[50] Karnell JL, Ettinger R. The interplay of IL-21 and BAFF in the formation and maintenance of human B cell memory[J]. Front Immunol, 2012,32(3):1-9

[51] Griffin DO, Holodick NE, Rothstein TL. Human B1 cells in umbilical cord and adult peripheral blood Express the novel phenotype $\mathrm{CD} 20^{+} \mathrm{CD} 27^{+} \mathrm{CD} 43^{+} \mathrm{CD} 70[\mathrm{~J}]$. J Exp Med, 2011,208(1):67-80

[52] Griffin DO, Rothstein TL. Human bl cell frequency: isolation and analysis of human bl cells[J]. Front Immunol, 2012,3122.

[53] Zhong XE, Gao WD, Degauque N, et al. Reciprocal Generation of Th1/Th17 and T-reg cells by B1 and B2B cells[J]. Eur J Immunol, 2007,37(9):2400-2404

[54] Kantor AB, Merrill CE, Herzenberg LA, et al. An unbiased analysis of $\mathrm{V}(\mathrm{H})-\mathrm{D}-\mathrm{J}(\mathrm{H})$ sequences from $\mathrm{B}$ la,B-1b,and conventional B cells[J]. J Immunol, 1997,158(3):1175-1186

[55] Baumgarth N. The double Life of a B-1 cell: self-reactivity selects for protective effector functions[J]. Nat Rev Immunol, 2011,11(1):34-46

[56] Descatoire M, Weill JC, Reynaud CA, et al. A human equivalent of mouse B-1 cells?[J]. J Exp Med., 2011,208(13):2563-2564

[57] Perez-Andres M, Grosserichter-Wagener C, Teodosio $\mathrm{C}$, et al. The Nature of circulating CD27(+)CD43(+) B cells[J]. J Exp Med, 2011,208(13):2565-2566

[58] Picard C, Bobby Gaspar H, Al-Herz W, et al.International union of immunological societies: 2017 primary immunodeficiency diseases committee report on inborn errors of immunity[J]. J Clin Immunol, 2018,38(1):96-128

[59] Israel L, Wang Y, Bulek K, et al. Human adaptive immunity rescues an inborn error of innate immunity $[\mathrm{J}]$. Cell, 2017,168(5):789

[60] Ma CS, Pittaluga S, Avery DT, et al. Selective Generation of functional somatically mutated $\operatorname{IgM}{ }^{+} \mathrm{CD} 27^{+}$, but not $\mathrm{Ig}$ isotype-switched,memory B cells in X-linked lymphoproliferative disease[J]. J Clin Invest, 2006,116(2):322-333

[61] Warnatz K, Bossaller L, Salzer U, et al. Human ICOS deficiency abrogates the germinal center reaction and provides a monogenic model for common variable immunodeficiency[J]. Blood, 2006,107(8):3045-3052

[62] Tangye SG, Good KL. Human $\operatorname{IgM}^{+} \mathrm{CD} 27^{+}$B cells: memory B cells or "memory" B cells? [J]. J Immunol, 2007,179(1):13-19.

[63] Seifert M, Kueppers R. Molecular footprints of a germinal center derivation of human $\operatorname{IgM}(+)(\operatorname{IgD}(+)) \mathrm{CD} 27(+) \mathrm{B}$ cells and the dynamics of memory B cell Generation $[\mathrm{J}]$. J Exp Med, 2009,206(12):2659-2669 
[64] Weill JC, Weller S, Reynaud CA. Human marginal zone B cells[J]. Annu Rev Immunol, 2005,23:161-196

[65] Rakhmanov M, Keller B, Gutenberger S, et al. Circulating CD21low B cells in common variable immunodeficiency resemble tissue homing, innate-like B cells[J]. Proc Natl Acad Sci U S A, 2009,106(32):13451-13456

[66] Warnatz K, Denz A, Drager R, et al. Severe deficiency of switched memory B cells $(\mathrm{CD} 27(+) \operatorname{IgM}(-) \operatorname{IgD}(-))$ in subgroups of patients with common variable immunodeficiency: a new approach to classify a heterogeneous disease[J]. Blood, 2002,99(5):1544-1551

[67] Weller S, Bonnet M, Delagreverie H, et al. $\operatorname{IgM}^{+} \operatorname{IgD}^{+}$ $\mathrm{CD} 27^{+} \mathrm{B}$ cells are markedly reduced in IRAK-4-, MyD88-, and TIRAP-but not UNC-93B-deficient patients[J]. Blood, 2012,120(25):4992-5001

[68] Treon SP, Xu L, Yang G, et al. MYD88 L265P somatic mutation in Waldenstrom's macroglobulinemia[J]. $N$ Engl J Med, 2012,367(9):826-833

[69] Lin SC, Lo YC, Wu H. Helical assembly in the MyD88IRAK4-IRAK2 complex in TLR/IL-1R signalling[J]. Nature, 2010,465(730):885-890

[70] Kawagoe T, Sato S, Matsushita K, et al. Sequential control of Toll-like receptor-dependent responses by IRAK1 and IRAK2[J]. Nat Immunol, 2008,9(6):684-691

[71] Gachard N, Parrens M, Soubeyran I, et al. IGHV gene features and MYD88 ${ }^{\text {L265P }}$ mutation separate the three marginal zone lymphoma entities and Waldenstrom macroglobulinemia/lymphoplasmacytic lymphomas[J]. Leukemia, 2013,27(1):183-189

[72] Poulain S, Roumier C, Decambron A, et al. MYD88 ${ }^{\text {L265P }}$ mutation in Waldenstrom's macroglogulinemia[J]. Blood, 2013,121(26):5259

[73] Varettoni M, Arcaini L, Zibellini S, et al. Prevalence and clinical significance of the MYD88 ${ }^{\text {L265P }}$ somatic mutation in Waldenstrom's macroglobulinemia and related lymphoid neoplasms[J]. Blood, 2013,121(13):25222528

[74] Xu L, Hunter ZR, Yang G, et al. MYD88 ${ }^{\mathrm{L} 265 \mathrm{P}}$ in waldenstrom macroglobulinemia, immunoglobulin $M$ monoclonal gammopathy, and other B-cell lymphoproliferative disorders using conventional and quantitative allele-specific polymerase chain reaction[J].Blood, 2013,121(11):2051-2058

[75] Loiarro M, Gallo G, Fanto N, et al. Identification of critical residues of the MyD88 death domain involved in the recruitment of downstream kinases[J]. J Biol Chem, 2009,284(41):28093-28103
[76] Yun S, Johnson AC, Okolo ON, et al. Waldenstrom macro globulinemia: review of pathogenesis and management[J]. Clin Lymphoma Myeloma Leuk, 2017,17(5):252-262

[77] Weber AN, Gloria YC, Cinar OA, et al.Oncogenic MYD88 mutations in lymphoma: novel insights and therapeutic possibilities[J]. Cancer Immunology Immunotherapy, 2018,67(11):1797-1807

[78] Wang L, Lawrence MS, Wan Y, et al. SF3B1 and other novel cancer genes in chronic lymphocytic leukemia[J]. N Engl J Med, 2011,365(26):2497-2506

[79] Ngo VN, Young RM, Schmitz R, et al. Oncogenically active MYD88 mutations in human lymphoma[J].Nature, 2011,470(7332):115-U133

[80] Pasqualucci L, Trifonov V, Fabbri G, et al. Analysis of the coding genome of diffuse large B-cell lymphoma[J]. Nat Genet, 2011,43(9):U33-830

[81] Puente XS, Pinyol M, Quesada V, et al. Wholegenome sequencing identifies recurrent mutations in chronic lymphocytic leukaemia[J]. Nature, 2011,475(7354):101-105

[82] Montesinos-Rongen M, Godlewska E, Brunn AA, et al. Activating L265P mutations of the MYD88 gene are common in primary central nervous system lymphoma[J].Acta Neuropathol, 2011,122(6):791-792

[83] Chakraborty R, Novak AJ, Ansell SM, et al. First report of MYD88L265P somatic mutation in IgM-associated light chain amyloidosis[J]. Blood, 2016,127(123):29362938

[84] Yang ZJ, Ellis T, Markant SL, et al. Medulloblastoma can be initiated by deletion of Patched in lineage-restricted progenitors or stem cells[J]. Cancer Cell, 2008,14(2):135-145

[85] Sunshine JC, Jahchan NS, Sage J, et al. Are there multiple cells of origin of Merkel cell carcinoma?[J]. Oncogene, 2018,37(11):1409-1416.

[86] Daley GQ, Van Etten RA, Baltimore D. Induction of chronic myelogenous leukemia in mice by the P210bcr/ abl gene of the Philadelphia chromosome[J]. Science,1990,247(4944):824-830

[87] Zhao C, Blum J, Chen AL, et al. Loss of beta-catenin impairs the renewal of normal and CML stem cells in vivo[J]. Cancer Cell, 2007,12(6):528-541

[88] Knittel G, Liedgens P, Korovkina D, et al. B-cell-specific conditional expression of Myd88p. L252P leads to the development of diffuse large B-cell lymphoma in mice[J]. Blood, 2016,127(22):2732-2741

(Received 02 December 2018, Revised 20 December 2018, Accepted 22 December 2018) 


\title{
Antibody
} 这迪溥猪

\section{JiangSu LIBO Medicine Biotechnology Co.,Ltd.}

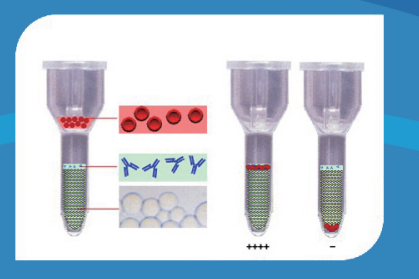

\author{
Microcolumn Gel Technology
}

\section{Professional Supplier of \\ Blood Diagnostic Reagents}
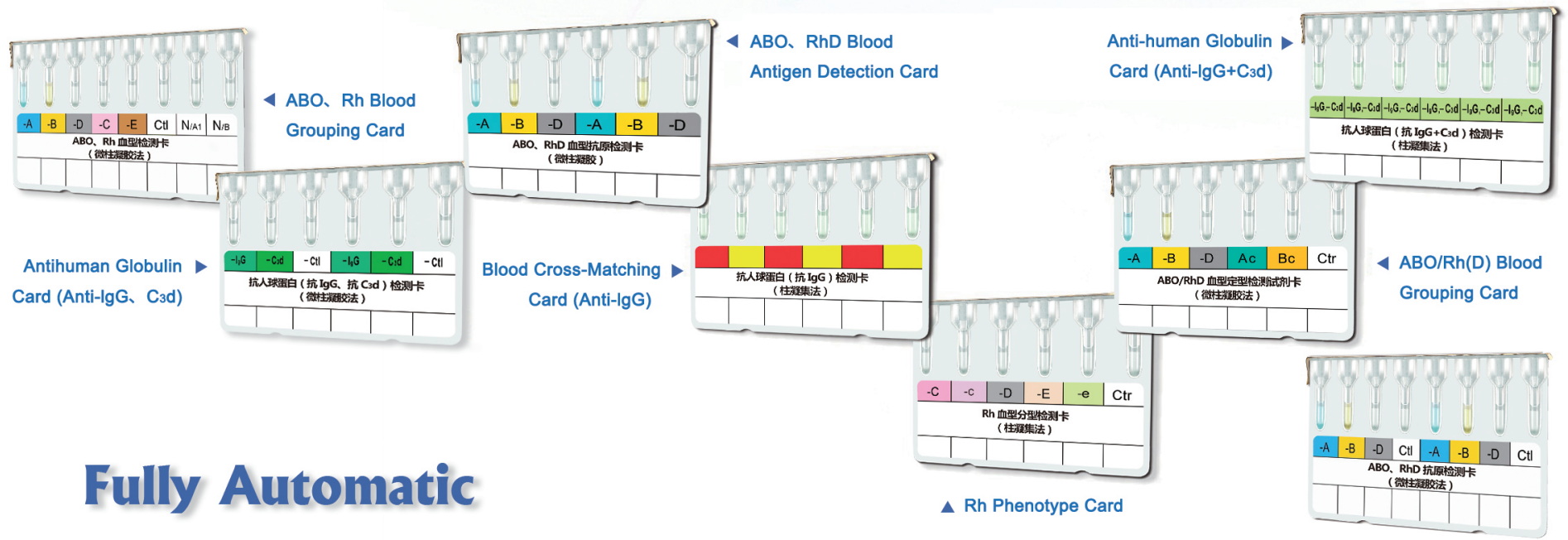

\section{Blood Grouping Analysis System}

A ABO, RhD Blood Detection Card

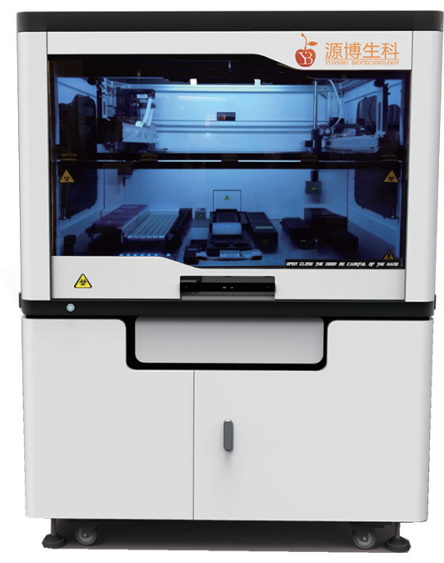

- Microcolumn gel immunoassay for

$\mathrm{ABO} / \mathrm{Rh}(\mathrm{D})$ blood grouping; Cross matching;

Antibody screening

- High throughout w/DUAL-centrifuge design

- Accuracy of sampling $\leq 2 \%$;

Repeatability of sampling CV $\leq 1.5 \%$

- Auto result acquisition and interpretation by CCD imaging system

\section{Antibod"} 安画溥猜

JiangSu LIBO Medicine Biotechnology Co.,Ltd.

Address: No 78 West Dongsheng Road, Jiangyin, Jiangsu214400, P.R. China

Web Site: www.libiotech.com

Sales Tel: +86-510-86990618、+86-510-86990633

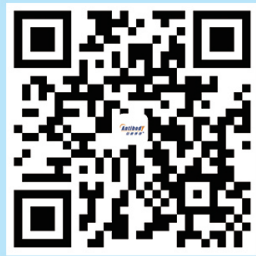

Tech Tel: +86-510-86990608、+86-510-86990655 